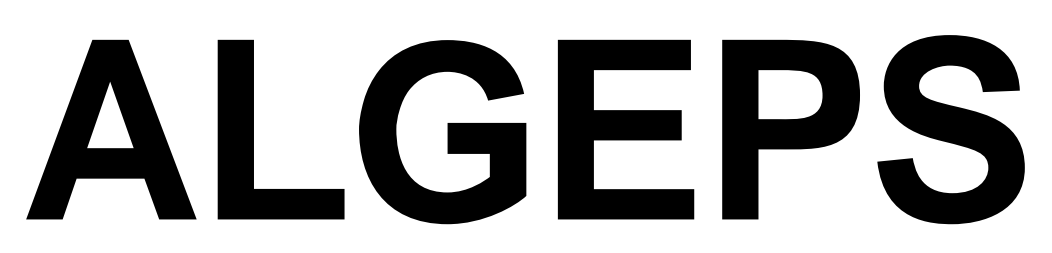

REVISTA DE GEOLOGIA, SÈRIE B no 580 - Febrer del 2012

ISSN $1132-7014$

D.L.B. 28.178 - 92

12 pàgines

\begin{abstract}
RECORRIDO DESDE MALÓN A EL BUSTE, A NUESTRA SEÑORA DE LA MISERICORDIA, BORJA Y MALEJÁN Y A VERA DEL MONCAYO, A TRAVÉS DEL PATRIMONIO GEOLÓGICO Y MINERO DE LAS COMARCAS DEL CAMPO DE BORJA Y DEL MONCAYO
\end{abstract}

Josep M. Mata-Perelló

Aquest recorregut va ésser experimentat amb docents el dia 1 DE JUNY DEL 2010 


\section{RECORRIDO DESDE MALÓN A EL BUSTE, A NUESTRA SEÑORA DE LA MISERICORDIA, BORJA Y MALEJÁN Y A VERA DEL MONCAYO, A TRAVÉS DEL PATRIMONIO GEOLÓGICO Y MINERO DE LAS COMARCAS DEL CAMPO DE BORJA Y DEL MONCAYO}

Por Josep M. Mata-Perelló

\section{ADVERTENCIAS PREVIAS}

Como en otros recorridos de RECONOCIMIENTO GEOLÓGICO (o de RECONOCIMIENTO GEOLÓGICO Y MINERO), el recorrido se compondrá de diversas PARADAS. En este caso serán seis.

Por otra parte, habrá que tener en cuenta, en todo momento, especialmente antes de empezar los recorridos de los diferentes tramos, el estado de los caminos y carreteras, por donde transitará el recorrido. Precisamente, en este itinerario, se discurrirá en una pequeña parte del recorrido por caminos de tierra, entre Maleján y las canteras de la Muela. Y también en los caminos de acceso a las canteras de la Sierra de las Perdices, al final del itinerario. Al respecto, cabe decir que prácticamente todos estos tramos se halla en buenas condiciones.

Finalmente, como ya hacemos en otros recorridos similares, queremos decir que hace falta tener un cuidado muy especial en el respeto a la naturaleza, a lo largo de todo el recorrido del itinerario, y también fuera de él.

\section{BREVE INTRODUCCIÓN GEOLÓGICA}

El recorrido de este itinerario, se desarrollará exclusivamente por una de las tres unidades geológicas que constituyen el suelo y el subsuelo de Aragón. Concretamente por la Depresión Geológica del Ebro (en donde se iniciarla y finalizara el recorrido del itinerario).

Así, a lo largo de todo de todo el recorrido del itinerario, se irán encontrando afloramientos cenozoicos, en su mayoría de carácter arcilloso y calcolutítico, pertenecientes generalmente al Mioceno. De entre estos materiales, cabe destacar los afloramientos carbonatados calcáreos de la Muela, los de las inmediaciones de Nuestra Señora de la Misericordia y los de la Sierra de las Perdices.

Asimismo, a menudo, encontraremos afloramientos de los materiales detríticos cuaternarios, por encima de los anteriores 


\section{BREVE INTRODUCCIÓN GEOGRÁFICA}

El recorrido del presente itinerario se efectuará exclusivamente por dos comarcas aragonesas. Así, se iniciará en la del Moncayo, en Malón (circulándose por esta comarca hasta sobrepasar el Buste), para entrar más adelante en la del Campo de Borja, tras dejar el Buste (y transitándose por esta comarca hasta más allá de Bulbuente). Finalmente, se volverá a entrar en la comarca del Moncayo, en el municipio de Vera de Moncayo, en donde finalizará el recorrido del itinerario.

En este recorrido, se circulará por los términos municipales de: Malón, Tarazona, el Buste y Vera de Moncayo (dentro de la comarca del Moncayo); y por los de Borja, Maleján y Bulbuente (dentro de la comarca del Campo de Borja).

\section{OBJETIVOS GENERALES DE ESTE ITINERARIO}

En este itinerario, los objetivos generales que se han de conseguir, se pueden concretar en los siguientes aspectos:

1.- Estudio y reconocimiento de los materiales cenozoicos (en buena parte del Mioceno) situados en la Depresión Geológica del Ebro, que iremos encontrando a lo largo del recorrido del itinerario, entre las inmediaciones de Malón y la Sierra de las Perdices (sita en el municipio de Vera de Moncayo, lindando con el de Tarazona).

2.- Visión de algunas de las antiguas explotaciones encontradas a lo largo del recorrido del itinerario. En concreto de;

2A) de diversas explotaciones de yeso, situadas en los municipios de Malón y de Tarazona.

2B) de diversas explotaciones de grava que veremos cerca de Malón, pero en el municipio de Tarazona

2C) de diversas explotaciones de calizas: las explotaciones más antiguas de los alrededores del Santuario de Nuestra Señora de la Misericordia, las de la Muela (cerca de Maleján), o las de la Sierra de las Perdices.

3.- Observación del impacto producido por las actividades mineras. I si se da el caso, de las restauraciones realizadas para paliar este impacto.

4.- Visión de los diferentes lugares directamente relacionados con el Patrimonio Geológico y Minero que iremos encontrando a lo largo del recorrido del presente itinerario

\section{ANTECEDENTES BIBLIOGRÁFICOS}

En relación con este itinerario, no conocemos ningún antecedente, relativo a otro itinerario que discurra por este lugar. En este sentido, este itinerario constituye un antecedente, si no estamos equivocados. Cabe mencionar otro itinerario nuestro (MATA-PERELLÓ, 2010, en un trabajo sobre el Campo de Borja. 
Por otra parte, haremos mención de algunos trabajos, de carácter geológico generalista, que corresponden a los trabajos del IGME (1972, 1974 y 1975), relativos al Mapa Geológico de España (a Escala 1.200.000), al Mapa Metalogenético de España y al Mapa de Rocas Industriales de España

Con respecto a las mineralizaciones que iremos encontrando, mencionaremos los trabajos de: CALVO (2001), CALVO et altri (1988); MAESTRE (1845); así como nuestros trabajos: MATA-PERELLÓ (1987 y 2000).

También mencionaremos el trabajo de PRAMES (2005) dedicado a la comarca del Bajo Martín. Así como el del GOBIERNO DE ARAGÓN (2001), dedicado a los Puntos de Interés Geológico de Aragón.

Finalmente, diremos que todos estos trabajos (así como otros que ahora no hemos aludido), figurarán mencionados, por orden alfabético, en el apartado dedicado a las REFERENCIAS BIBLIOGRÁFICAS.

\section{RECORRIDO DEL ITINERARIO}

Este recorrido se iniciará en las inmediaciones del pueblo de Malón (dentro de la comarca del Moncayo o del Somontano del Moncayo). En torno a ese pueblo se haran dos paradas, pero dentro del término de Tarazona. Luego, dentro de la misma comarca, el recorrido se dirigirá hacia Conchillos y hacía el Buste,. Ahí se efectuará una nueva primera parada dentro de este itinerario.

Luego, el recorrido se dirigirá (pasando de la comarca del Moncayo a la del Campo de Borja) hacía el Santuario de Nuestra Señora de la Misericordia, por donde realizaremos una nueva parada. Tras ello, el recorrido se dirigirá hacía Borja y hacía Maleján, por donde se realizaran diversas paradas, en el recorrido del itinerario.

Finalmente, tras sobrepasar Bulbuente (en donde no se hará ninguna parada) el itinerario se dirigirá hacía la Sierra de las Perdices, pasando de nuevo a la comarca del Moncayo, tras entrar en el término de Vera del Moncayo. En esa sierra se efectuaran las últimas paradas, finalizando el itinerario.

\section{DESCRIPCIÓN DEL ITINERARIO}

Como de costumbre, haremos una serio de PARADAS (o ESTACIONES), en donde se realizaran diversas explicaciones en torno a las características del lugar en donde se halla la PARADA. Por otra parte, en ellas haremos mención del término municipal dónde se encuentran, así como del número del "Mapa Topográfico Nacional (a escala 1:50.000, que indicaremos entre paréntesis. Así, ahora (en este recorrido) utilizaremos solamente dos hojas: concretamente la $\mathbf{3 2 0}$ (o de Tarazona) y $\mathbf{3 5 2}$ (o de Tabuenca). 
Así, la relación ordenada de las paradas que constituyen el recorrido de este itinerario, es la siguiente:

PARADA 1. YESERAS DE LA UGUERA, (término municipal del Tarazona, comarca del Moncayo). (Hoja 320).

El recorrido del presente itinerario lo iniciaremos en la localidad de Malón, situada en la comarca zaragozana del Moncayo. Concretamente, lo haremos a la salida de la población yendo hacía el Sur, hacía unas yeseras pertenecientes al término municipal de Tarazona.

Este lugar se halla situado dentro de la Depresión Geológica del Ebro, entre afloramientos de los materiales miocénicos que la rellenan. Estos materiales son los que aparecen en este lugar, siendo de naturaleza yesosa. Estos materiales han sido explotados en este lugar, aunque de forma muy rudimentaria. Cabe indicar la presencia de un horno de yeso.

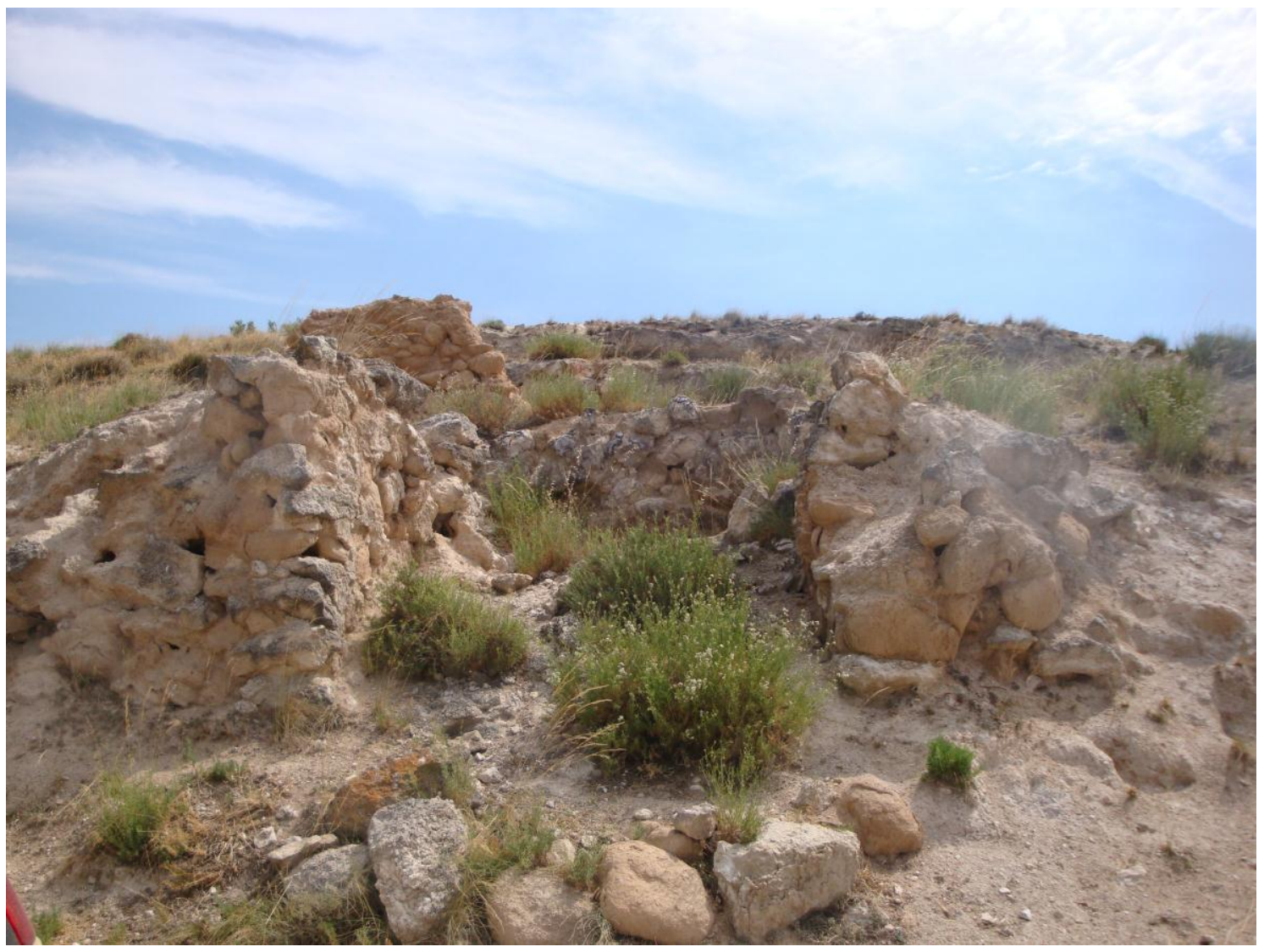

Horno de yeso de Tarazona, cerca de Malón

PARADA 2. GRAVERAS DE MALÓN, (término municipal de Malón, comarca del Moncayo). (Hoja 320).

Tras efectuarla parada anterior, conviene regresar al pueblo de Malón, con la finalidad de tomar la carretera de Tarazona. A unos $2 \mathrm{Km}$ del pueblo (y a 3’5 de la parada anterior) efectuaremos una nueva parada. 
En este recorrido, habremos continuado siempre dentro de la Depresión Geológica del Ebro, entre afloramientos de los materiales miocénicos, cubiertos a menudo por depósitos cuaternarios. Esto es lo que ocurre en este lugar. Aquí aparecen unas terrazas fluviales del río Queiles, que han sido explotados en varias graveras ahora abandonadas.

\section{PARADA 3. EL CAOS DEL BUSTE, (término municipal del Buste, comarca del Moncayo). (Hoja 320).}

Después de realizar la parada anterior, conviene seguir por la carretera que conduce a Tarazona. Así se pasará por: Vierlas y por Conchillos. En este último pueblo nos convendrá seguir por la carretera que se dirige a la localidad del Buste. Tras cruzarla, haremos una parada a la salida de ella, a unos 10 de la anterior.

En este recorrido, y en el lugar de la parada, nos hallamos dentro de la Depresión Geológica del Ebro. Así, por doquier veremos afloramientos de los materiales cenozoicos del Mioceno.

Desde este lugar de observación, podemos ver el afloramiento de los materiales carbonatados miocénicos, que luego veremos en la parada siguiente. Estos materiales se hallan profundamente fracturados. Ello ha propiciado una espectacular caída de bloques sobre las zonas más bajas. Precisamente, este relieve ruiniforme es un interesante patrimonio geológico de la comarca del Moncayo, en donde nos hallamos ahora.

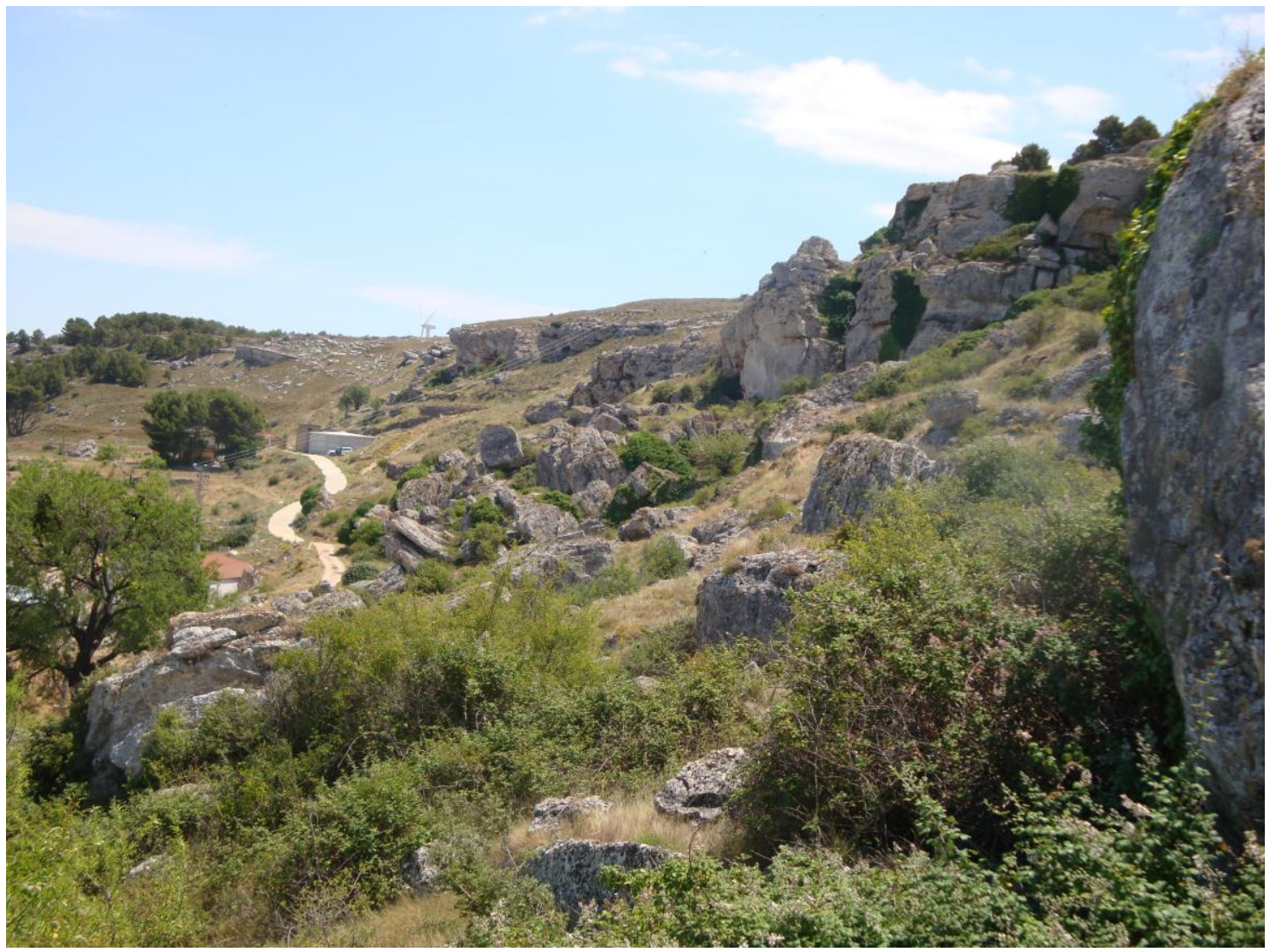

Un aspecto del relieve ruiniforme del Buste 


\section{PARADA 4. EL HORNO DE CAL, (Nuestra Señora de la Misericordia, término municipal de Borja, comarca del Campo de Borja). (Hoja 320).}

Después de realizar la parada anterior, conviene continuar por la carretera, yendo siempre hacía la población de Borja. Al llegar a las inmediaciones del Santuario de Nuestra Señora de la Misericordia, efectuaremos una nueva parada, a unos $5 \mathrm{Km}$ de la parada anterior, tras haber pasado de la comarca del Moncayo a la del Campo de Borja, en donde estamos ahora.

En este recorrido, habremos ido encontrando afloramientos de los materiales miocénicos y de los materiales cuaternarios de los que hemos hablado anteriormente. Estos materiales se sitúan dentro de la Depresión Geológica del Ebro, en donde estamos y por donde efectuaremos todo el recorrido del presente itinerario.

En este lugar afloran los niveles de calizas miocénicas de las que hemos hablado en la parada anterior. Estas calizas han sido explotadas en este lugar, hace algunos años, pudiéndose ver la explotación aún, sin restaurar. Las calizas extraídas se utilizaron en parte para un horno de cal, situado en la misma explotación. Los restos del horno, así como los de la tolva, forman parte del patrimonio minero de la comarca del Campo de Borja, a pesar de su mal estado de conservación.

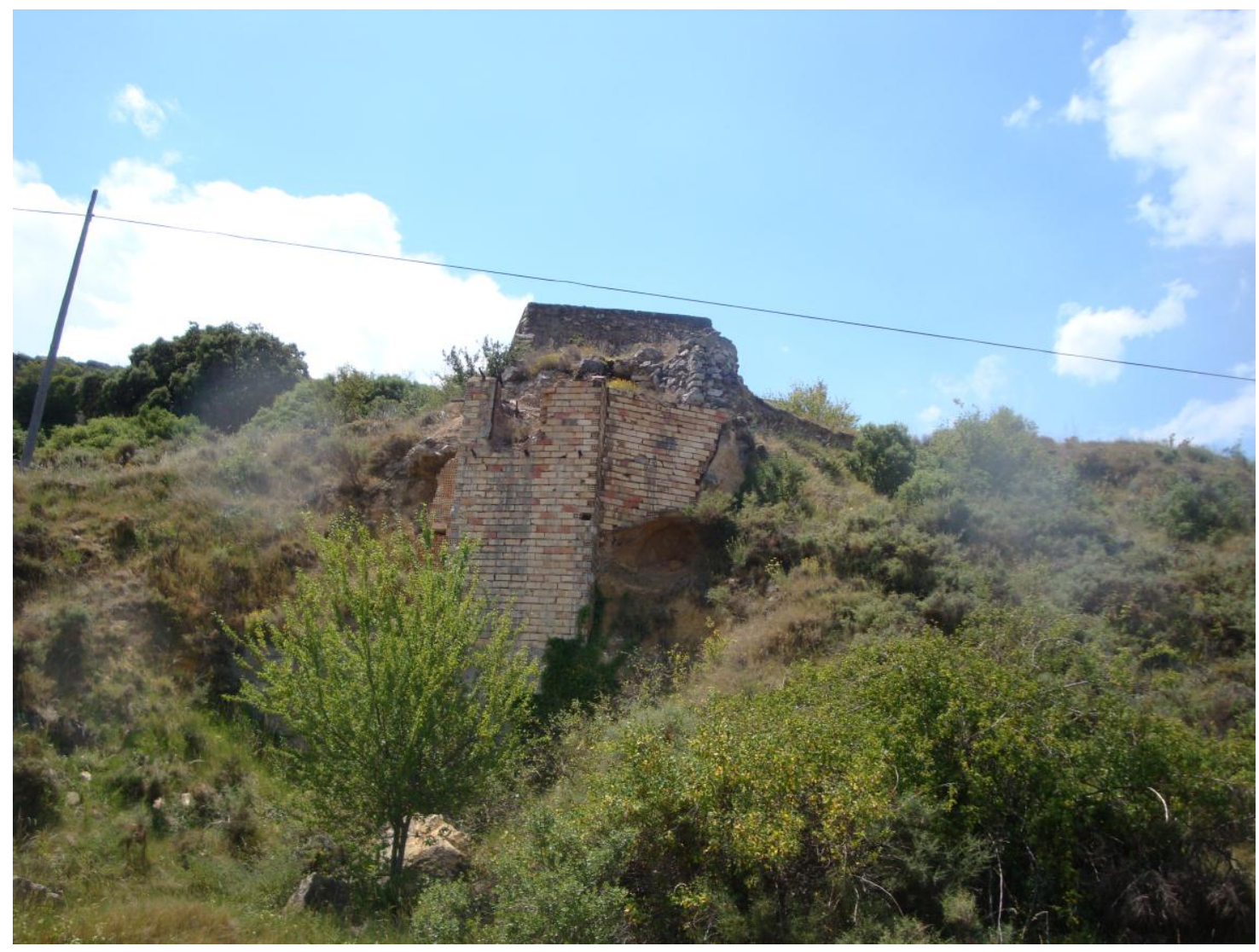

Restos de la tolva y del horno de cal 


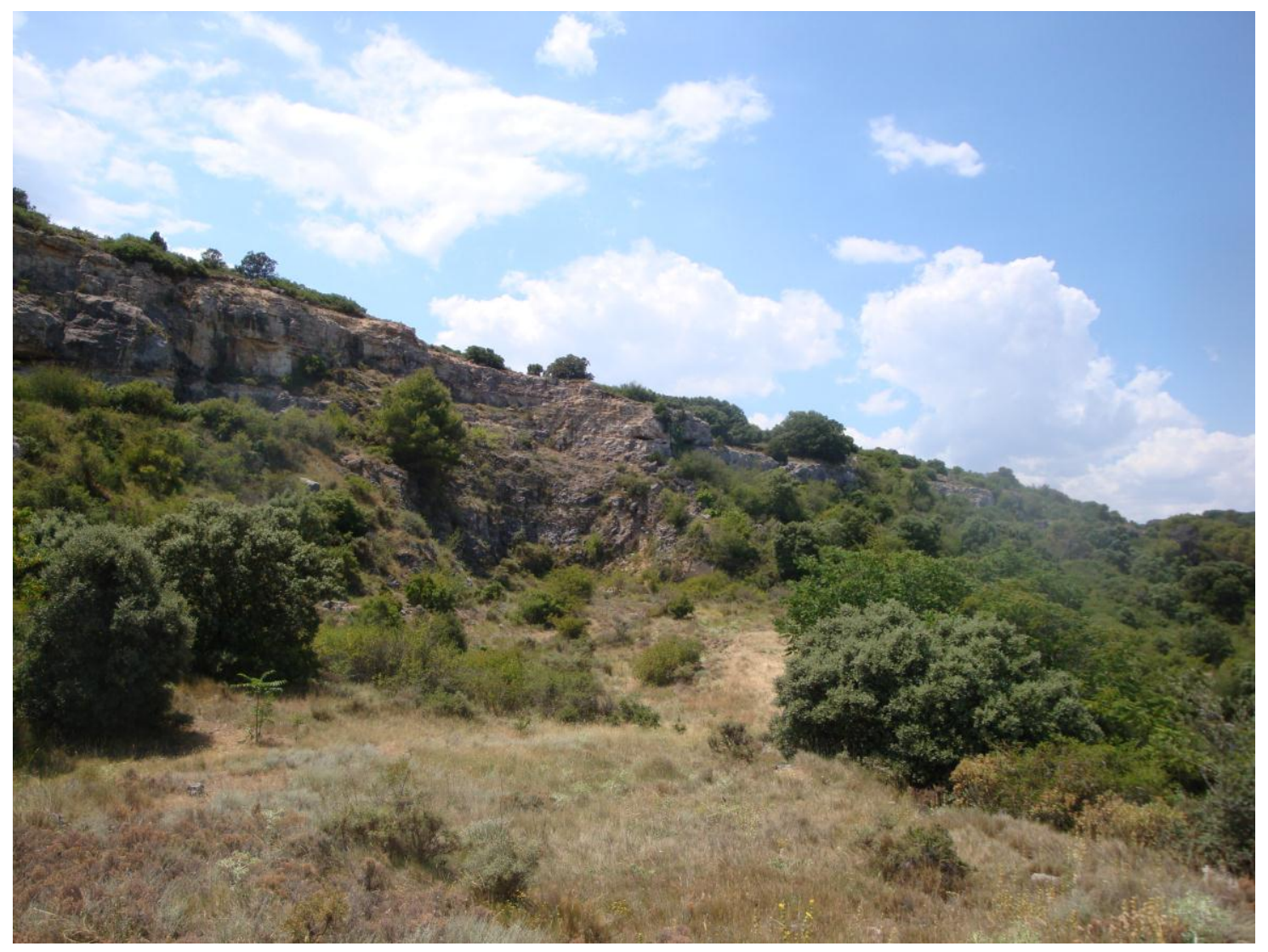

Un aspecto de la explotación

PARADA 5. CANTERAS DEL CERRO DE LA MUELA. (término municipal de Borja, comarca del Campo de Borja). (Hoja 352).

Tras efectuar la parada anterior, conviene dirigirnos hacía la población de Borja, atravesándola, con la intención de continuar ahora por la carretera nacional N-122, yendo hacía la cercana población de Maleján. Una vez en ella, nos convendrá tomar el camino que conduce hacía la Muela. Al llegar ahí, haremos una nueva parada (la última de este itinerario). Esta parada la haremos en unas canteras actualmente en explotación. Así, desde la parada anterior habremos recorrido unos $15 \mathrm{Km}$ para llegar hasta aquí.

En este recorrido, habremos ido encontrando en todo momento los materiales miocénicos (y cuaternarios) que hemos estado viendo desde el inicio del recorrido en el Buste. Estos materiales rellenan, en este sector, la Depresión Geológica del Ebro, la única unidad geológica que habremos encontrado en este itinerario.

Así, tras encontrar los niveles de yesos en las inmediaciones de Borja, después habremos visto afloramientos de materiales lutíticos y arenosos, que nos habrán ido acompañando hasta casi llegar al lugar de la parada.

Sin embargo, cerca del lugar de la parada se han empezado a hacer ostensibles los afloramientos de los materiales carbonatados. Estos materiales que sobresalen en la topografía de la zona, han dado lugar a los relieves de la Muela. Estos releves son tabulares, pidiéndose ver buenos ejemplos de relieve en cuesta por doquier. 
En este lugar, estos materiales carbonatados son explotados en una gran cantera (que se halla en activo, por lo que se requiere permiso para poder entrar en ella). Estos materiales carbonatados, una vez triturados son machacados, con la finalidad de ser utilizados como áridos para la construcción.

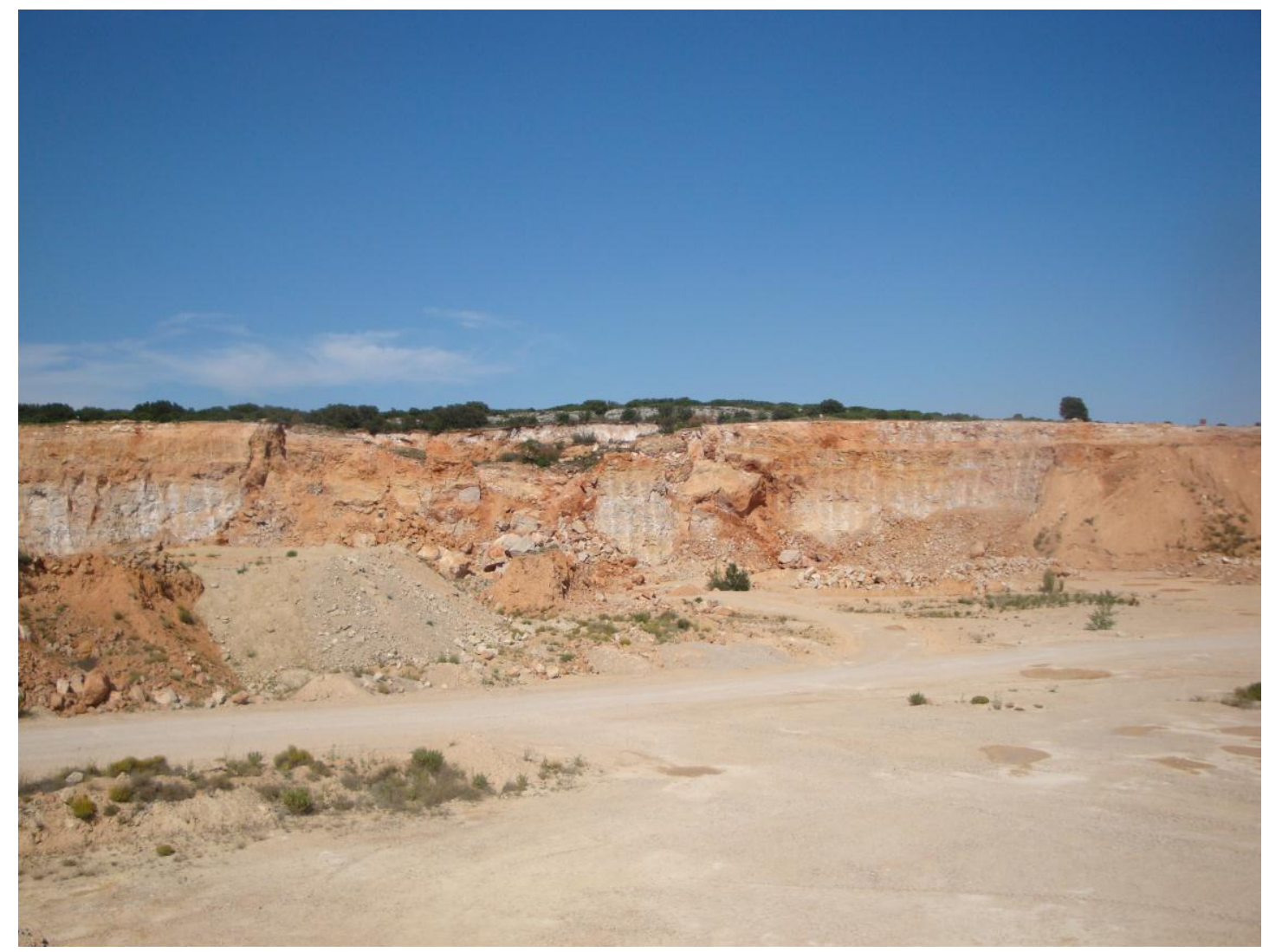

Un aspecto de la cantera en explotación

PARADA 6. CANTERAS DE LA SIERRA DE LAS PERDICES, (término municipal de Vera de Moncayo, comarca del Moncayo). (Hoja 320).

Tras efectuar la parada anterior, conviene dirigirnos de nuevo hacía la población de Maleján. A partir de ahí, continuaremos por la carretera N-211, dirigiéndonos hacía el poniente. Pronto pasaremos por el pueblo de Bulbuente. Más adelante, dejaremos por la izquierda la carretera de Vera de Moncayo. Tras ello empezaremos a subir el Puerto de las Lanzas. Antes de llegar arriba, convendrá tomar un camino por la derecha que va a la Sierra de las Perdices. Al llegar ahí efectuaremos la última parada, a unos $15 \mathrm{Km}$ de la anterior. En este recorrido hemos pasado de la comarca del Campo de Borja a la comarca del Moncayo, en donde ahora estamos.

Como en los anteriores recorridos, nos hemos movido siempre entre afloramientos de los materiales miocénicos, que son los que rellenan la Depresión Geológica del Ebro, en donde estamos ahora situados. 
En este lugar ha habido diversas explotaciones de unos niveles carbonatados miocénicos. Y junto a las explotaciones se hallan unos hornos de cal (o caleras), muy rudimentarios.

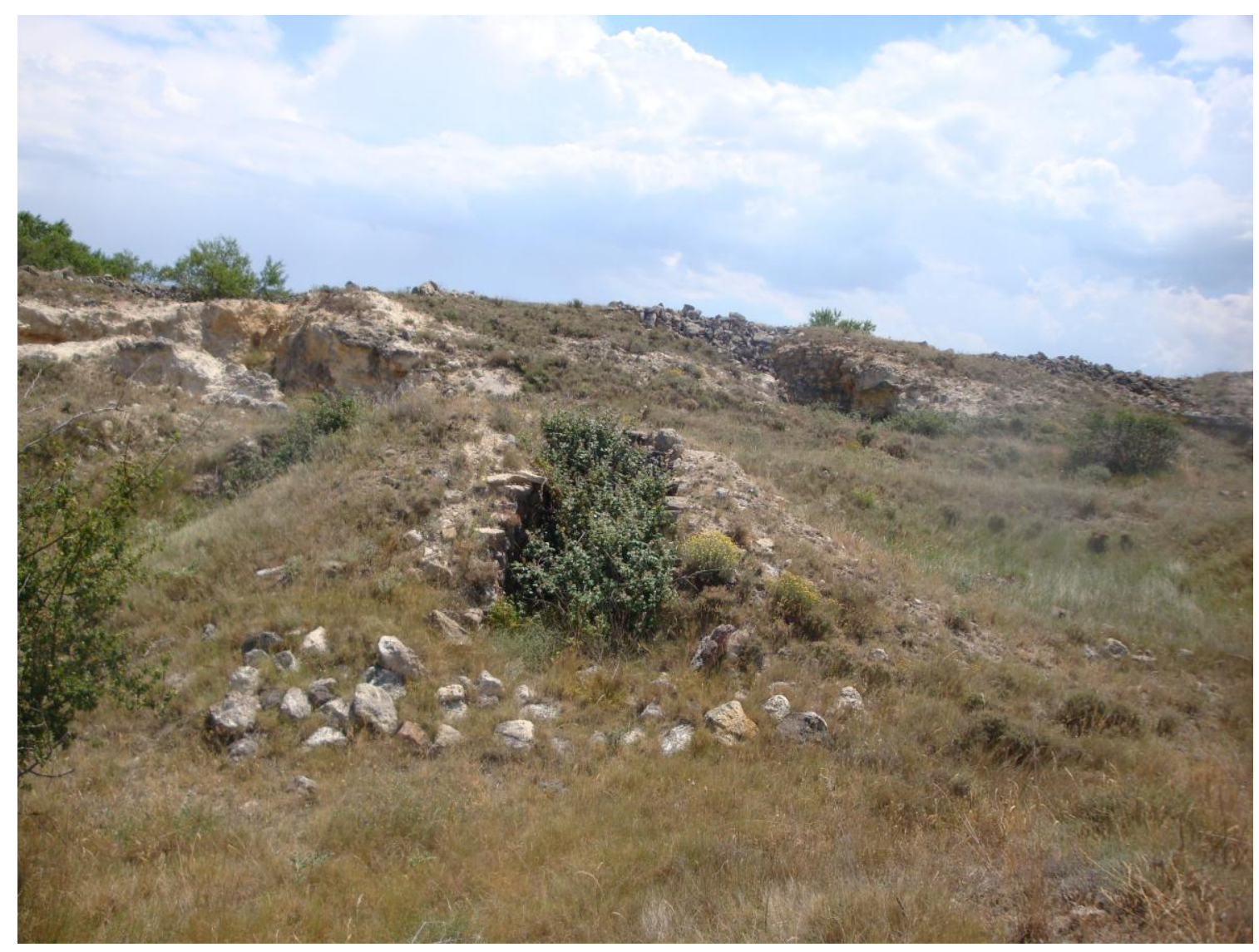

Horno de cal de la Sierra de las Perdices (Vera del Moncayo)

\section{EN ESTE LUGAR FINALIZA EL ITINERARIO}

\section{BIBLIOGRAFÍA}

CALVO, M. (2001).- Las Minas de Sal de Remolinos, Zaragoza. Revista de Minerales, Vol. 2, $\mathrm{n}^{\circ}$ 2, pp. 3 - 22. Barcelona

CALVO, M. et altri (1988). - Minerales de Aragón, Colección Temas Geológicos, 207 Pág. Zaragoza

GOBIERNO DE ARAGÓN (2001).- Puntos de Interés Geológico de Aragón. Consejería de Medio Ambiente del Gobierno de Aragón. Zaragoza

IGME (1972).- Mapa Geológico de España a escala 1:200.000 (Síntesis de la cartografía existente). Hoja y Memoria no. 32 (Zaragoza). Inst. Geol. Min. España 
IGME (1973).- Mapa Metalogenético de España a escala 1:200.000. Hoja y Memoria $n^{\circ} .32$ (Zaragoza). Inst. Geol. Min. España

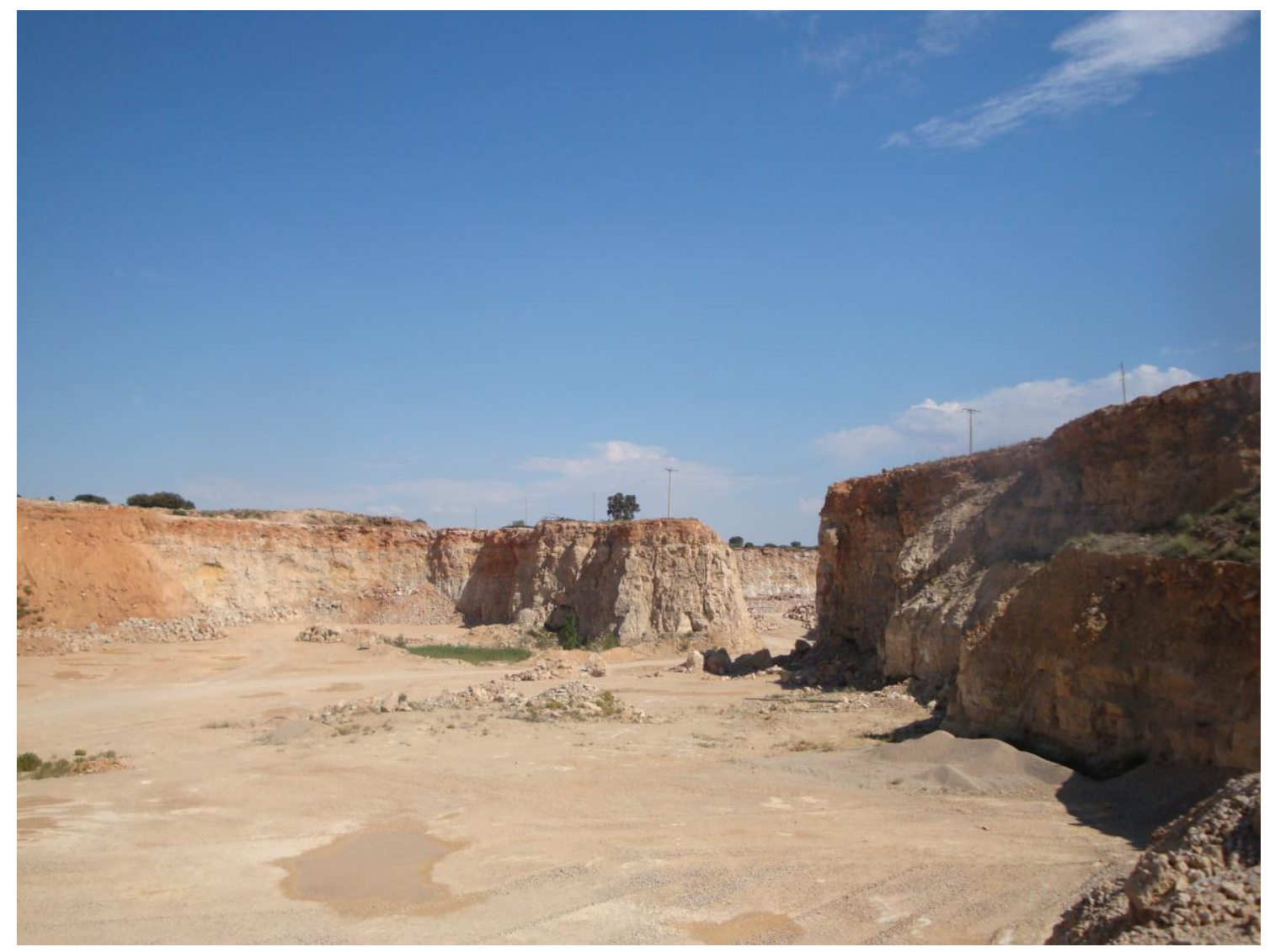

CANTERA DE LA MUELA, BORJA (CAMPO DE BORJA)

IGME (1975).- Mapa de Rocas Industriales de España a escala 1:200.000. Hoja y Memoria $n^{\circ} .32$ (Zaragoza). Inst. Geol. Min. España

MAESTRE, A. (1845).- Descripción geognóstica del Distrito Minero de Cataluña y Aragón. Anales de Minas, t. III. Madrid

MATA - PERELLÓ, J.; (1987).- Introducción al conocimiento de las mineralizaciones aragonesas. Mineralogistes de Catalunya, t.III, pp. 258-265. Barcelona

MATA - PERELLÓ, J.M. (2000).- Inventario Mineralógico de la comarca del Campo de Borja, Rodeno, 35. 21 Pág. Manresa

MATA - PERELLÓ, J.M. (2000).- Inventario Mineralógico de la comarca del Moncayo, Rodeno, 38. 24 Pág. Manresa

MATA - PERELLÓ, J.M. (2010).- Recorrido desde el Buste (comarca del Moncayo) a Nuestra Señora de la Misericordia, Borja y Maleján, a través del patrimonio geológico y 
minero de la comarca del Campo de Borja. Pp. 269 - 278, Informe sobre el Patrimonio Geológico y Minero de la comarca del Campo de Borja. Manresa

PRAMES (2005).- Campo de Borja. Colección RUTASCAL por Aragón. Prames, Gobierno de Aragón. 119 pag. Zaragoza.

PRAMES (2005).- Comarca del Moncayo. Colección RUTASCAL por Aragón. Prames, Gobierno de Aragón. 119 pag. Zaragoza. 